\title{
Antiproliferative activity of gambogic acid isolated from Garcinia hanburyi in Hep3B and Huh7 cancer cells
}

\author{
PARRY NGAN HON LEE and WING SHING HO
}

\author{
School of Life Sciences, The Chinese University of Hong Kong, Hong Kong, SAR, P.R. China
}

Received November 8, 2012; Accepted December 28, 2012

DOI: 10.3892/or.2013.2291

\begin{abstract}
The anticancer activities of gambogic acid (GA) on two hepatocellular carcinoma cells with either p53 deletion (Hep3B) or p53 mutation (Huh7) were investigated in the present study. GA inhibited the growth of Hep3B and Huh7 through similar apoptotic pathways. After treatment of Hep3B and Huh7 with GA for $24 \mathrm{~h}$, the $\mathrm{IC}_{50}$ was determined for both cell lines at 1.8 and $2.2 \mu \mathrm{M}$, respectively. The results showed that both cancer cells underwent morphological changes and DNA fragmentation. GA induced apoptosis in the two cell lines through caspases-3/7, -8 and -9 in the mitochondrial pathway. The results suggest that both the caspases in the extrinsic death receptor pathway and the mitochondrial-dependent pathway are involved in the GA-induced cell apoptosis. The inhibitory effects of GA on Hep3B and Huh7 are independent of p53-associated pathway.
\end{abstract}

\section{Introduction}

Liver cancer remains one of the leading causes of cancerrelated mortality. Herbal medicine is a valid source of new therapeutic agents since an immense chemical diversity is found in different herb medicines. Some of the active principles from herbal medicines have been isolated and characterized for cancer drug development. Herbal medicine offers promise with its complementary role in the cancer treatment with cancer drugs. Gambogic acid (GA) is one of the naturally occurring compounds present in a brownish-to-orange resin called gamboge, which is derived from Garcinia hanburyi (Fig. 1). Garcinia hanburyi has a long history of medicinal use in Southeast Asia, and it is used as a folk medicine and coloring agent (1). An improved separation method for the determination of twelve xanthones in gamboges from Garcinia hanburyi enabled researchers to purify GA from Garcinia hanburyi (2). Previous studies have reported that GA has potent antitumor activity via induction of reactive oxygen species accumulation

Correspondence to: Professor Wing Shing Ho, School of Life Sciences, Mong Man Wai Building 612, The Chinese University of Hong Kong, Hong Kong, SAR, P.R. China

E-mail:ws203ho@cuhk.edu.hk

Key words: apoptosis, gambogic acid, cancer, caspase which consequently led to apoptosis of SMMC-7721 cells (3). GA was reported to covalently modify $\mathrm{I} \kappa \mathrm{B}$ kinase $\beta$ subunit to inhibit lipopolysaccharide-induced activation of $\mathrm{NF}-\kappa \mathrm{B}$ in macrophages (4). Other studies showed GA mediated the control of nucleophosmin and nucleoporins in the programmed cell death of Jurkat cells (5). GA caused microtubule depolymerization and phosphorylation of c-Jun N-terminal kinase-1 leading to cell cycle arrest in MCF-7 cells (6). The induction of apoptosis in cancer cells is vital in cancer treatment. The present study explored the antitumor activity of GA in Hep3B and Huh7 human liver cancer cell lines.

\section{Materials and methods}

Chemicals and reagents. Trypsin-EDTA (1X), Dulbecco's minimal essential medium (DMEM), Roswell Park Memorial Institute (RPMI)-1640 medium, penicillin-streptomycin (PS) antibiotic mixture (100X) and qualified fetal bovine serum (FBS) were purchased from Invitrogen. Chemicals and reagents were of analytical grade purchased from Sigma Chemicals, St. Louis, MO, USA. Dimethylsulfoxide (DMSO) was purchased from Fisher Scientific, USA. Bromophenol Blue, Agarose, Tris-Base, Boric Acid, $\mathrm{NaCl}$ and SDS powder were ordered from USB, Cleveland, OH, USA. Ethanol was purchased from BDH.

Cell culture and treatment. Hep3B, Huh7 and WRL68 were purchased from ATCC and cultured according to their protocols. GA was a generous gift from the Chinese Medicine Laboratory, Hong Kong Jockey Club Institute of Chinese Medicine, and was isolated by the established method (2). GA was prepared by dissolving $4 \mathrm{mg}$ of dry GA into $1 \mathrm{ml}$ of DMSO. Cancer cells were seeded in a 96-well plate at the density of $5.0 \times 10^{5}$ cells/well and treated with various concentrations of GA for $24 \mathrm{~h}$. Methylthiazoletetrazolium (MTT) solution $(5 \mathrm{mg} / \mathrm{ml})$ was added to the assay mixture and incubated for $4 \mathrm{~h}$. The culture media was removed prior to addition of DMSO. Each experiment with GA treatment was repeated three times. By comparing the absorbance of the wells of cells treated with different concentrations of GA with the control, the viability of cells after GA treatment was calculated. The concentration of GA that reduced the cell viability of $50 \%\left(\mathrm{IC}_{50}\right)$ was recorded.

DNA extraction. The 100 bp DNA ladder was from Fermentas and the Cell Death Detection ELISA kit was purchased from 
Roche Applied Science. The cell samples were processed according to the manufacturer's protocols. The supernatant was subsequently removed and the DNA pellet was allowed to air dry for 15 to $20 \mathrm{~min}$. TE buffer (20-50 $\mu \mathrm{l})$ containing $0.2 \mathrm{mg} / \mathrm{ml}$ of RNase A was added to the DNA pellet. The samples were incubated at $37^{\circ} \mathrm{C}$ for $90 \mathrm{~min}$ to completely dissolve the sample. The DNA solution $(2 \mu \mathrm{l})$ was added to $998 \mu 1 \mathrm{TE}$ buffer and the concentration was measured using UV spectrophotometry (DU 650; Beckman-Coulter) with $\mathrm{OD}_{260}$.

DNA agarose gel electrophoresis. Ten microliters of the dissolved DNA samples were mixed with $2 \mu 16$ X DNA loading dye. The mixtures were loaded on the $2 \%$ agarose gel and run at $75 \mathrm{~V}$ for $1 \mathrm{~h}$. The DNA bands were examined under UV illuminator and the gel was photographed for documentation.

DAPI stain. Changes in cell morphology during apoptosis were examined by fluorescence microscopy of DAPI-stained cells. The monolayer of cells was washed in PBS and fixed with $4 \%$ paraformaldehyde for $30 \mathrm{~min}$ at room temperature. The fixed cells were permeabilized with $0.2 \%$ Triton X-100 in PBS three times and incubated with $1 \mu \mathrm{g} / \mathrm{ml}$ of DAPI for $30 \mathrm{~min}$. The cells were washed with PBS three times. The apoptotic nuclei (intensely stained, fragmented nuclei and condensed chromatin) were examined under $\mathrm{x} 400$ magnification using a fluorescent microscope with a $340 / 380 \mathrm{~nm}$ excitation filter for at least two investigations.

Cell death detection with ELISA. ELISA was carried out according to the manufacturer's protocol (Invitrogen). The cells were incubated with different concentrations of GA in a 96-well plate for $24 \mathrm{~h}$ prior to centrifugation at $200 \mathrm{x}$ g for $10 \mathrm{~min}$. The lysis buffer $(200 \mu \mathrm{l})$ was added to lyse the cell pellet. The plate was kept at room temperature for $30 \mathrm{~min}$ prior to centrifugation at $200 \mathrm{x} \mathrm{g}$ for $10 \mathrm{~min}$. The supernatant $(20 \mu \mathrm{l})$ was placed in the streptavidin-coated plate for analysis. The immunoreagent $(80 \mu \mathrm{l})$ was added to the well and covered by aluminum foil with shaking at $300 \mathrm{rpm}$ for $2 \mathrm{~h}$. The solution in each well was removed and the well was rinsed with $250 \mu \mathrm{l}$ incubation buffer three times. ABTS solution of $100 \mu \mathrm{l}$ was added into the wells prior to shaking in the plate shaker at $250 \mathrm{rpm}$ for color development. After 10-20 min, $100 \mu 1$ ABTS Stop Solution was added to stop the reaction and the well was measured at $405 \mathrm{~nm}$. Absorbance of wells was recorded and the enrichment factor, which shows the extent of apoptosis in the GA-treated cells, was calculated by the following expression: (absorbance of the GA-treated sample-blank)/(absorbance of the vehicle-treated sample-blank).

Protein expression in GA-induced cells. The antibodies, anti-p53, anti-Bcl-2, anti-Bax, anti-caspase-8 and anti-PARP, were purchased from Santa Cruz Biotechnology, Inc. Anticytochrome $c$, anti-Bid and anti-GAPDH were purchased from BD Pharmingen. For HRP-secondary antibodies, anti-mouse and anti-rabbit antibodies were obtained from Invitrogen. Cells $\left(1 \times 10^{6}\right)$ were seeded into a $100 \mathrm{~mm}$ dish. Different concentrations of GA were added prior to incubation for 4 , 8,12 and $24 \mathrm{~h}$. The cell samples were spun at $14,000 \mathrm{x} \mathrm{g}$ for $15 \mathrm{~min}$. The supernatant of the samples was collected for

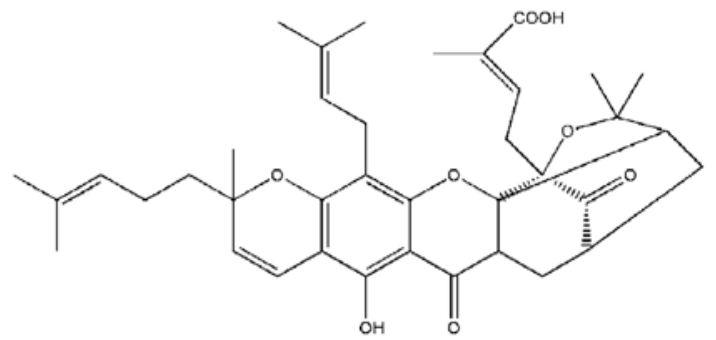

Figure 1. Chemical structure of gambogic acid.

protein concentration determination according to the Bio-Rad Protein Assay protocol.

Extraction of cytosolic and mitochondrial protein fraction. Cells were collected and counted prior to the addition of the cytosolic protein lysis buffer $(50 \mu \mathrm{l})$. The sample was vortexed for $30 \mathrm{sec}$ and centrifuged at $14,000 \mathrm{x}$ g for $1 \mathrm{~min}$ at $4^{\circ} \mathrm{C}$. A volume of $2 \mathrm{X}$ SDS sample loading buffer was added to the supernatant. The whole cell lysis buffer and 2X SDS sample loading buffer were added to completely lyse the sample.

Protein gel electrophoresis by SDS-PAGE. The electrophoresis system, Mini-PROTEAN ${ }^{\circledR}$ II cell from Bio-Rad, was used to perform sodium dodecyl sulfate-polyacrylamide gel electrophoresis (SDS-PAGE). The resolving gel solution (10\%) was set and poured into the gel casting form. The top of the gel was layered with $50 \mu \mathrm{l}$ of isopropanol and the gel was left for $30 \mathrm{~min}$. Stacking gel solution (4\%) was added onto the top of the resolving gel. A 15-tooth comb was inserted and the gel was allowed to polymerize for $40 \mathrm{~min}$. The samples mixed with $2 \mathrm{X}$ sample loading dye were boiled at $100^{\circ} \mathrm{C}$ for $10 \mathrm{~min}$. After samples were loaded onto the wells, the gel was run at constant voltage at $150 \mathrm{~V}$ for $1 \mathrm{~h}$ in $1 \mathrm{X}$ running buffer.

Western blotting. The SDS-PAGE was completed when the dye front (blue in color) reached the bottom of the gel. The gel was removed and immersed into transfer buffer. The Whatman $3 \mathrm{MM}$ paper (6 pieces/gel) and PVDF membrane were cut into the same dimension as the resolving gel. The PVDF membrane was washed with $100 \%$ methanol for $1 \mathrm{~min}$ and was immersed into the transfer buffer. The Whatman papers were soaked into the transfer buffer. A gel sandwich was assembled with the PVDF membrane and the resolving gel layered between two stacks of Whatman papers in the semi-dry Trans-Blot electroblotter (Bio-Rad). Proteins were transferred to the membrane at constant voltage at $10 \mathrm{~V}$ for $1.5 \mathrm{~h}$. The membrane was collected and rinsed briefly with TBST buffer. Then, the membrane was immersed into blocking solution with primary antibody for $16 \mathrm{~h}$ at $4^{\circ} \mathrm{C}$ with continuous agitation. The primary antibody used was mouse monoclonal anti-p53 (1:1,000), anti-BID (1:1,000), anti-Bcl-2 (1:1,000), anti-Bax (1:500), anti-cytochrome $c$ $(1: 2,000)$, anti-caspase-8 $(1: 1,000)$, anti-PARP $(1: 1,000)$, antitransferrin receptor $(1: 1,000)$ and anti-GAPDH $(1: 5,000)$. The unbound primary antibody was removed by washing with TBST for $20 \mathrm{~min}$, thrice. The membrane was immersed into secondary antibody (goat anti-mouse HRP/mouse anti-rabbit HRP) for $1 \mathrm{~h}$ at room temperature with slow agitation. The excess antibody was removed by washing with TBST three 


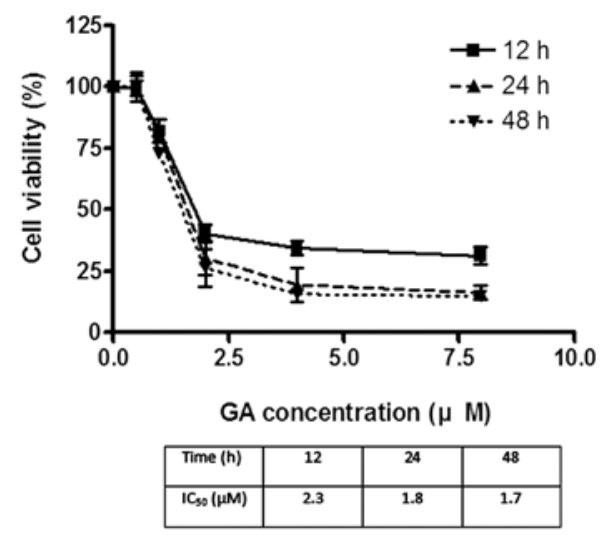

Figure 2. Hep3B cells were incubated with different concentrations of GA for 12,24 and $48 \mathrm{~h}$. The viability of the cells was measured by MTT assay and calculated as percentage of the solvent control. The $\mathrm{IC}_{50}$ values in different concentrations are listed in the table $(n=3)$.

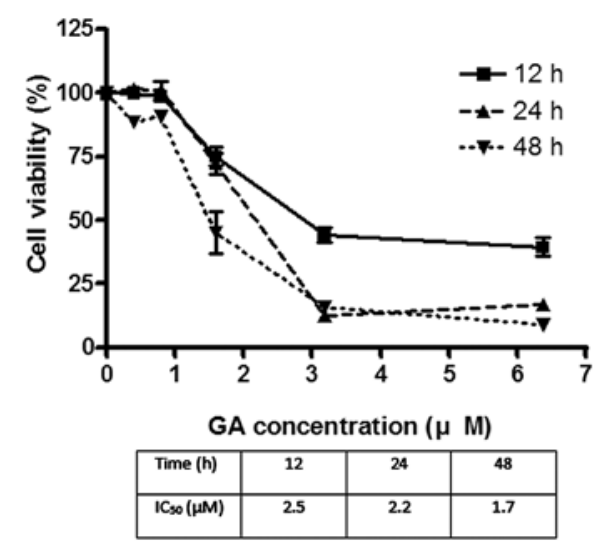

Figure 3. Huh7 cells were seeded in a 96-well plate with different concentrations of GA. The viability of the cells was measured by MTT assay and calculated as percentage of the solvent control. The $\mathrm{IC}_{50}$ values in different concentrations were recorded $(n=3)$.

times (20 min). Millipore Immobilon Western HRP kit ( $0.5 \mathrm{ml}$ of each reagent) was applied to the membrane for 3 to $5 \mathrm{~min}$. After removing excess reagent, protein bands on the membrane were visualized and recorded on Fuji Super RX film (Fujifilm). Intensity of the bands was measured using ImageJ program.

Immunoprecipitation. Cells were seeded into $100 \mathrm{~mm}$ dishes. After $24 \mathrm{~h}$, different concentrations of GA $(2,1,0.5 \mu \mathrm{M})$ were added before incubation for another $24 \mathrm{~h}$. The cells were collected and lysed in CHAPS buffer. The concentration of the lysate was measured and diluted $500 \mu \mathrm{g}$ protein $/ 500 \mu \mathrm{l}$ buffer. The anti-Bax 6A7 monoclonal antibody $(2 \mu \mathrm{g})$ was added to the diluted lysate and the mixture was incubated overnight at $4^{\circ} \mathrm{C}$. After the incubation, $25 \mu \mathrm{l}$ of protein A-agarose gel bead was added and the lysate was incubated for $3 \mathrm{~h}$. The gel beads were washed three times using the CHAPS buffer and collected by centrifugation at $14,000 \mathrm{x}$ g for $10 \mathrm{~min}$. The sample loading dye $(50 \mu \mathrm{l})$ was added to the beads prior to boiling for $10 \mathrm{~min}$, followed by a centrifugation of $14,000 \mathrm{x} \mathrm{g}$ at $4^{\circ} \mathrm{C}$. The supernatant was subjected to western blot analysis using mouse anti-Bax antibody.

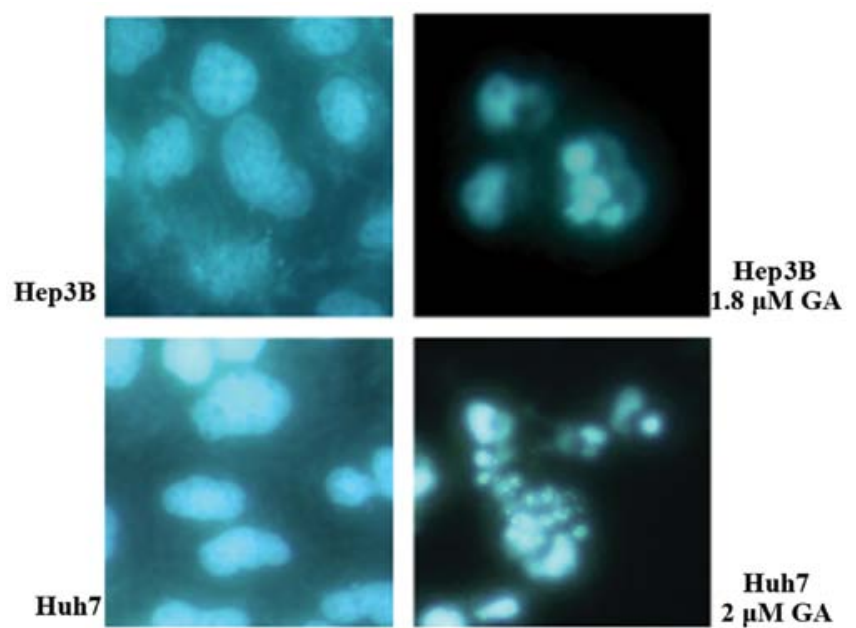

Figure 4. Hep3B and Huh7 cells were treated with different concentrations of GA for $24 \mathrm{~h}$. Cells were stained with DAPI, a fluorescence dye that binds to DNA. Inverted fluorescence microscopy was used and the image was photographed. Nuclear condensation and also fragmentation of DNA in the apoptotic cells was detected.

Caspase cascade study of GA-induced cancer cells. Apo-One ${ }^{\mathrm{TM}}$ caspase-3/7 assay kit was purchased from Promega. Caspase inhibitor z-IETD-fmk and z-LEDH-fmk were from Calbiochem. Trypan blue was purchased from Invitrogen. Hemocytometer was obtained from Sigma Chemicals. Caspase-3/7 activity was examined using Apo-One ${ }^{\mathrm{TM}}$ Caspase-3/7 Assay kit (Promega). Cells (Hep3B or Huh7) were seeded in a 96-well plate in the medium for $24 \mathrm{~h}$ followed by GA treatment of the cell lines. Subsequently, z-DEVD-rhodamine 110 from the assay kit was added into the well. After $2 \mathrm{~h}$ of incubation at room temperature, the fluorescence intensity of the wells was measured by a fluorescence plate reader at excitation $492 \mathrm{~nm}$ and emission $535 \mathrm{~nm}$.

\section{Results}

GA induces apoptosis in hepatocellular cells. The effects of GA on the viability of Hep3B and Huh7 were investigated using MTT assay. GA effectively reduced the viability of cancer cells after incubation for $24 \mathrm{~h}$. The $\mathrm{IC}_{50}$ of GA for Hep3B was 1.8 and $2.2 \mu \mathrm{M}$ for Huh7 (Figs. 2 and 3). After treatment of cells with GA, cell shrinkage and budding were recorded. DNA fragmentation and condensation were visualized by the DAPI staining investigation using fluorescence microscopy (Figs. 4 and 5). DNA fragmentation was detected after GA treatment in HCC cell lines (Fig. 5). The amount of cytosolic DNA fragment was determined with cell ELISA kit (Fig. 6). The results showed that the amount of DNA in the cytosol significantly increased after addition of GA. Apoptosis is characterized by the occurrence of cell shrinkage and membrane blebbing (7). In addition, chromatin condensation and DNA cleavage shown by DAPI staining (Fig. 4) also indicated apoptosis (8). To avoid ambiguity, DNA fragmentation, another hallmark of apoptosis, was examined after the treatment of GA on the cell lines for $24 \mathrm{~h}$. The result of agarose gel electrophoresis showed the presence of DNA ladders (Fig. 5). During apoptosis, mono- and oligonucleosomes are released into the cytoplasm before the plasma membrane breaks down $(9,10)$. The cytoplasmic content of the 


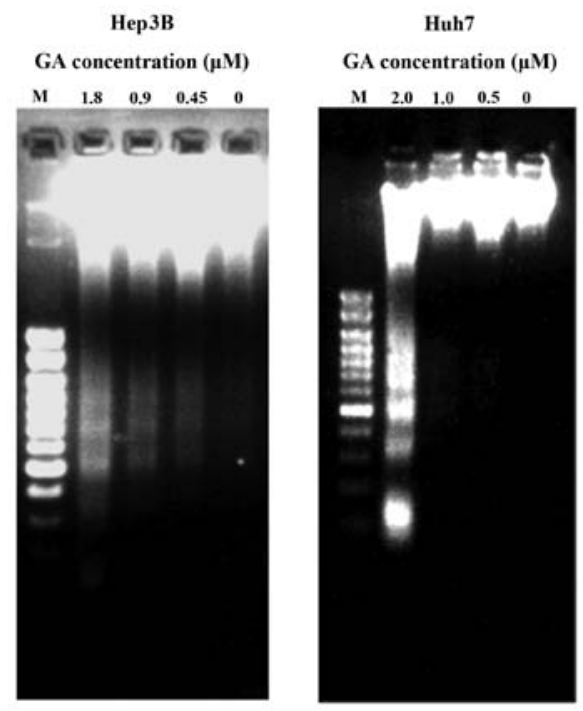

Figure 5. Agarose gel electrophoresis shows the fragmentation of DNA in GA-incubated HCC cell lines. HepG2 cells were treated with different concentrations of GA for $24 \mathrm{~h}$. DNA from the cells was extracted and electrophoresed through a $2 \%$ agarose gel, which was visualized using ethidium bromide staining. The lane marked with $\mathrm{M}$ shows the electrophoresis result of the 100-bp marker.

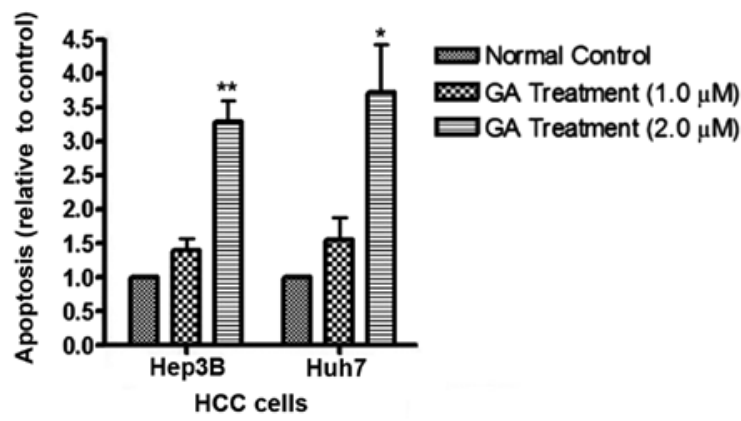

Figure 6. The HCC cells were treated with different concentrations of GA for $24 \mathrm{~h}$. The amount of the cytosolic DNA was isolated according to the manufacturer's protocols and measured using the histone specific antibody. The measured amount of the DNA in the GA-treated cells was divided by that of the solvent-treated control and the extent of apoptosis is shown in the figure $\left(\mathrm{n}=3 ;{ }^{*} \mathrm{P}<0.05 ;{ }^{* *} \mathrm{P}<0.01\right)$.

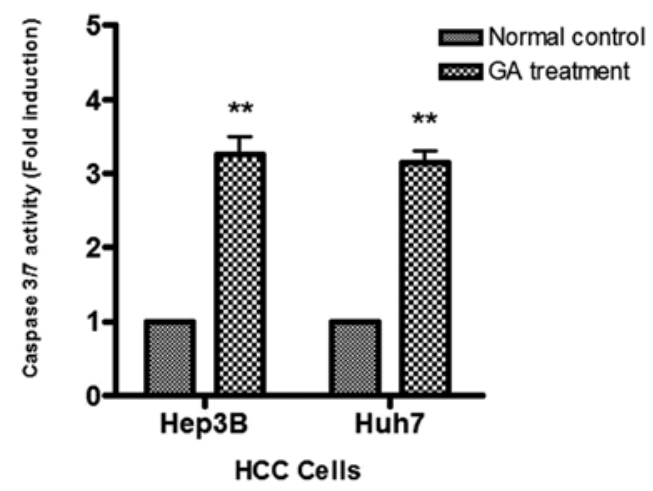

Figure 7. Caspase-3/7 activities of the $\mathrm{HCC}$ cells after GA treatment were measured by Apo-One ${ }^{\mathrm{TM}}$ caspase-3/7 assay kit. The cell lines were seeded into 96-well plates and incubated with GA $(2 \mu \mathrm{M})$ for $24 \mathrm{~h}$. The substrate, z-DEVDrhodamine 110, was added and incubated for another $2 \mathrm{~h}$. Fluorescence intensities of the wells were then measured using excitation wavelength $492 \mathrm{~nm}$ and emission wavelength $535 \mathrm{~nm}$. The caspase activities of the GA-treated cancer cells were compared to their untreated control $\left(\mathrm{n}=3 ;{ }^{* *} \mathrm{P}<0.01\right)$.

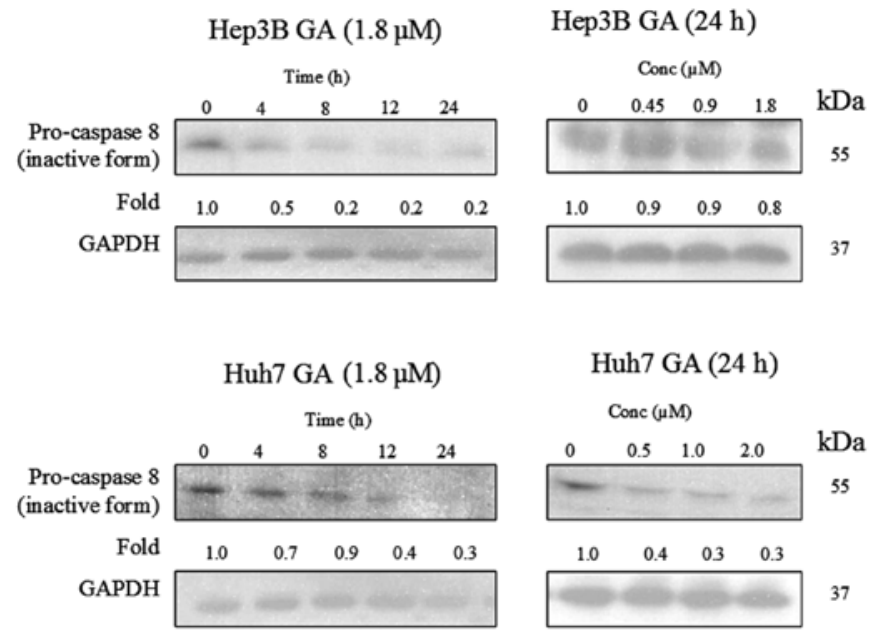

Figure 8. Western blot analysis of three individual experiments shows the cleavage of pro-caspase- 8 , the inactive form of caspase- 8 . HCC cells were treated with different concentrations of GA for different periods of time. GAPDH was used as the control protein. The intensity of the bands was measured by software ImageJ. Fold change relative to control was calculated using pro-caspase-8: GAPDH ratio.

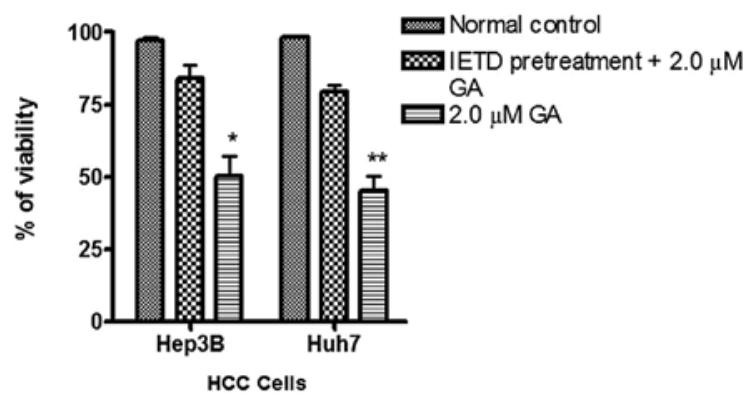

Figure 9. GA-induced apoptosis is associated with caspase-8. HCC cells were treated with GA for $24 \mathrm{~h}$ or pretreated with z-IETD-fmk $(20 \mu \mathrm{M})$ for $4 \mathrm{~h}$ followed by incubation with GA for $24 \mathrm{~h}$. The survival rates of the cells were measured by Trypan Blue exclusion test, which is more sensitive than MTT assay. The percentage of viability was calculated by the number of survival cells over the total number of the cells in the assay $\left(\mathrm{n}=3 ;{ }^{*} \mathrm{P}<0.05 ;{ }^{* *} \mathrm{P}<0.01\right)$.

tested cells was collected and the amount of released DNA was detected by the ELISA kit. The results showed that following GA treatment, the levels of cytoplasmic DNA in HCC cells was markedly elevated (Fig. 7). These results provide evidence that GA mediated cell death through apoptosis.

Caspase cascade studies in GA-induced apoptosis. To study caspase activity in the GA-induced apoptosis, Apo-One ${ }^{\mathrm{TM}}$ Caspase-3/7 Assay was used. An increase of caspase-3/7 activity was found in the two HCC cells after GA treatment (Fig. 7). The activation of caspase- 8 in the death receptor pathway and caspase- 9 in the mitochondrial pathway were determined using western blot analysis (Figs. 8-10). The results indicate that the cleavage of the active form of caspases- 8 and -9 after GA-treatment occurred in a time- and dose-dependent manner (Fig. 11).

Caspase-8 activation in GA-treated cells leads to Bid cleavage. The involvement of Bid and its relationship with caspase- 8 activation in GA-induced apoptosis were investigated. Full 

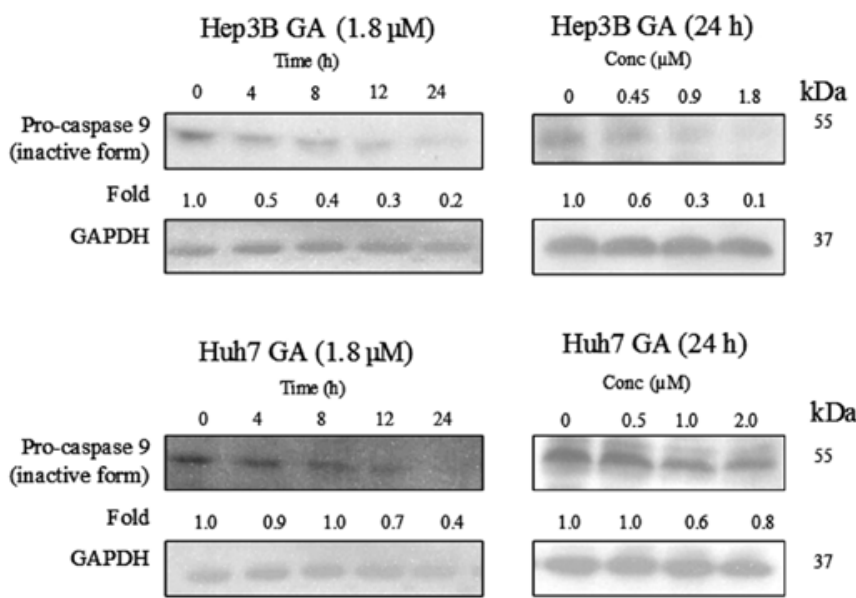

Figure 10. Western blot analysis shows the cleavage of pro-caspase- 9 , the inactive form of caspase-9. HCC cells were treated with different concentrations of GA for different periods of time. GAPDH was used as the control protein. The intensity of the bands was measured by software ImageJ. Fold change relative to control was calculated using pro-caspase-9: GAPDH ratio.

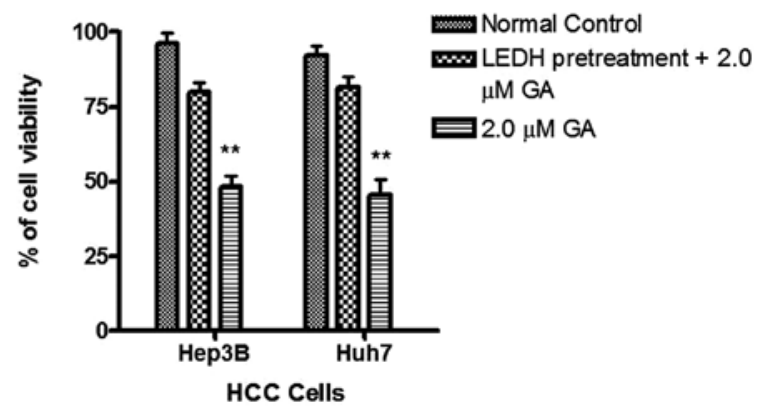

Figure 11. GA-induced apoptosis is associated with caspase-9. HCC cells were treated with GA for $24 \mathrm{~h}$ or pretreated with z-LEDH-fmk $(50 \mu \mathrm{M})$ for $4 \mathrm{~h}$ followed by incubation with GA for $24 \mathrm{~h}$. The viability of the cells was measured by Trypan Blue exclusion test. The percentage of viability was calculated by the number of survival cells over the total number of the cells in the assay $\left(\mathrm{n}=3 ;{ }^{* *} \mathrm{P}<0.01\right)$.
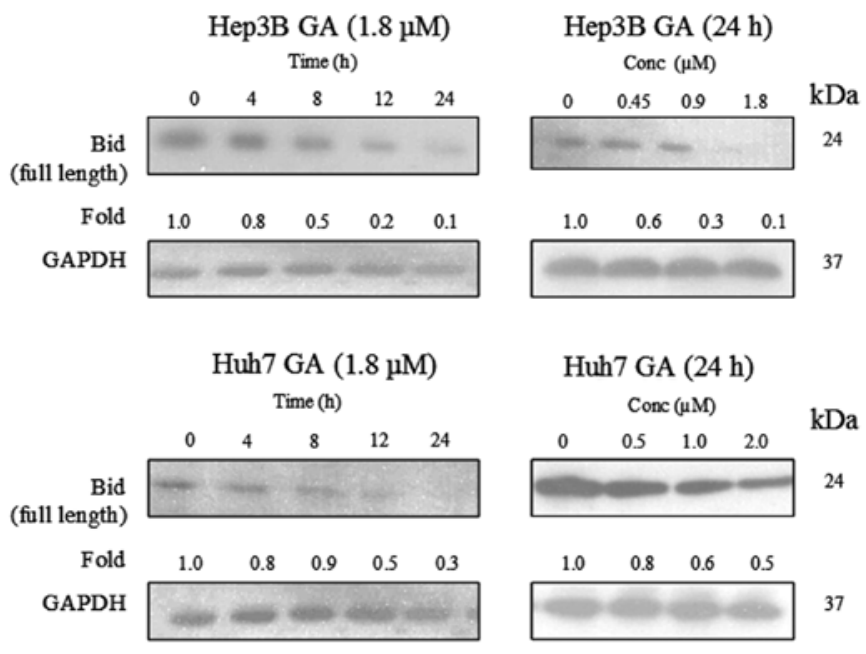

Figure 12. Western blot analysis shows the level of full length Bid, the inactive form of Bid after treatment with GA for different periods of time. GAPDH was used as the control protein. The intensity of the bands was measured by software ImageJ. Fold change relative to control was calculated using Bid:GAPDH ratio. The data represent the average of three individual experiments in each set.

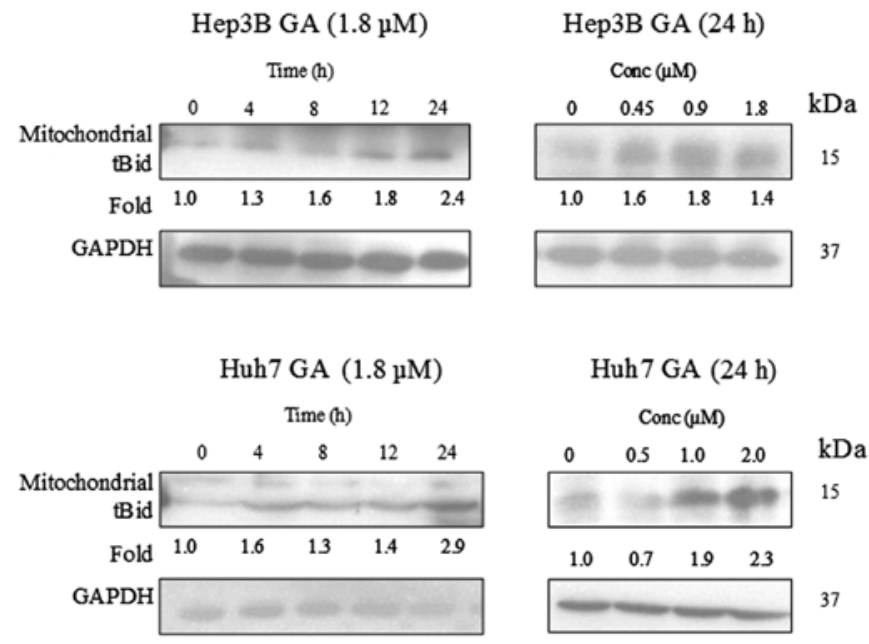

Figure 13. Western blot analysis shows the cleavage of Bax. HCC cells were treated with different concentrations of GA for different periods of time. GAPDH was used as the control protein. The intensity of the bands was measured by software ImageJ. Fold change relative to the control was calculated using Bax:GAPDH ratio.

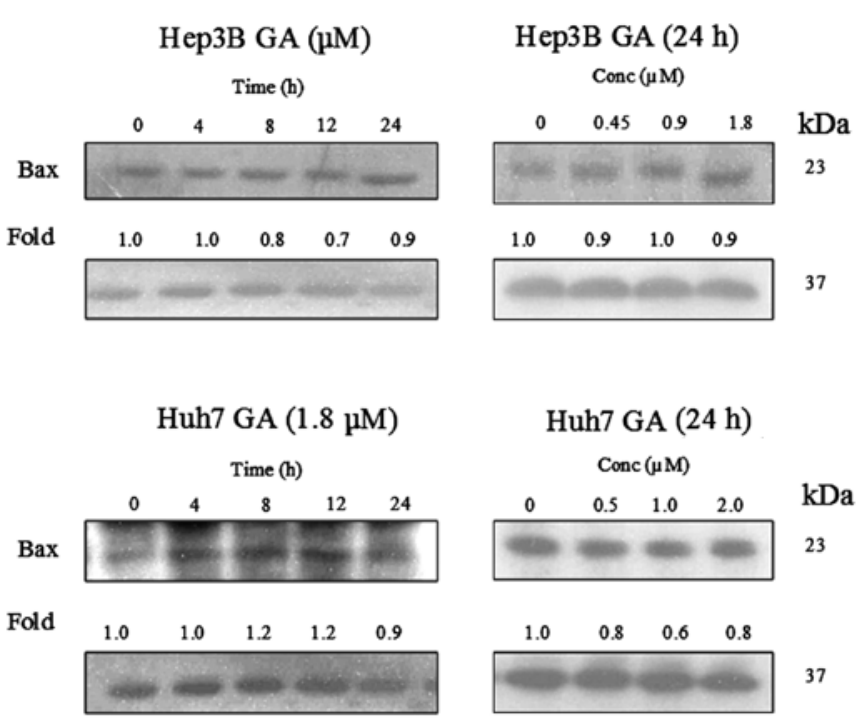

Figure 14. Western blot analysis shows the level of Bax in the cytosol and mitochondria. The cells were lysed using digitonin according the manufacturer's protocols. The mitochondrial and cytosolic fractions were collected and subjected to western blot analysis. Level of GAPDH in the cytosol was used as the control. The intensity of the bands was measured by software ImageJ. Fold change relative to the control was calculated using Bax:GAPDH ratio. The results represent the average of three individual experiments.

length Bid (24 kDa) was found to be cleaved in a time- and dose-dependent manner upon GA treatment (Fig. 12). A cell fractionation experiment was performed to investigate the level of tBid in the mitochondria. Fig. 13 indicates an accumulation of tBid in the mitochondria in the HCC cell line.

GA induces Bax conformational changes and cytochrome c release. It has been reported that Bax plays an important role in Bid-mediated apoptosis through conformational change and mediation of signaling process $(11,12)$. Fig. 14 shows that the expression level of Bax was constant in GA-induced apoptosis. In order to further examine the role of Bax in GA-induced 

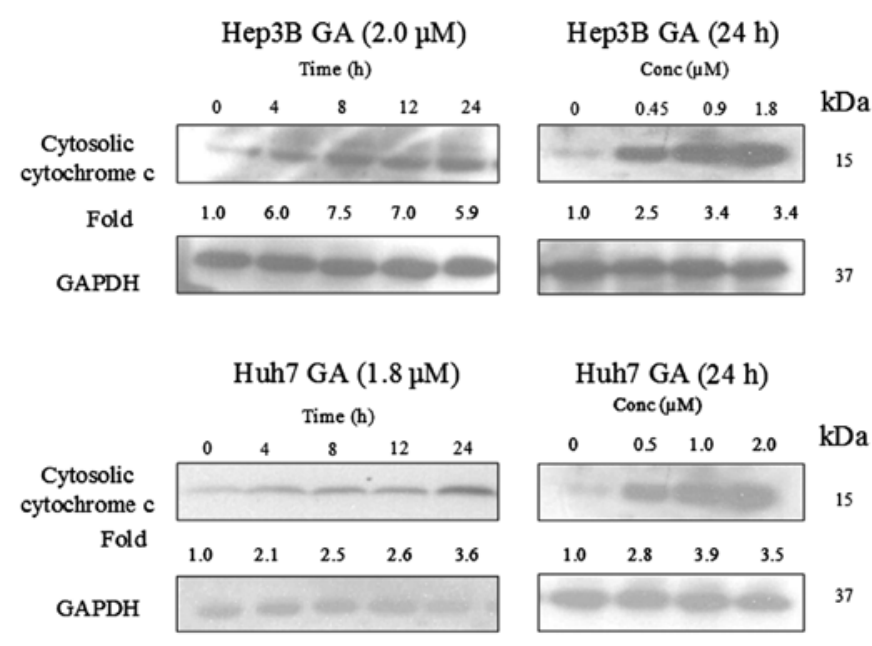

Figure 15. Western blot analysis showing the level of cytochrome $c$ in the cytosol. HCC cells were treated with different GA concentrations for various times as indicated. The mitochondrial and cytosolic fractions were collected and subjected to western blot analysis. The intensity of the bands was measured by software ImageJ. The data represent the average of three individual experiments.

apoptosis, immunoprecipitation (IP) of Bax using Bax (6A7) monoclonal antibody was performed. This antibody recognizes the Bax protein with conformational change but not the native form (11). It was reported that the conformational change of Bax was triggered by the truncated form of Bid (tBid) (13). This tBid is subsequently translocated to the mitochondria with Bax. The translocation of tBid to mitochondria was shown in western blot analysis (Fig. 15). Cytochrome $c$, which is originally present in the mitochondria, was released.

\section{Discussion}

In the present study we provided insights into the effects of GA on the inhibition of two different types of liver cancer cells. Present chemotherapy based on the treatment of liver cancer with drugs is not yet satisfactory. Specific anticancer agents against different types of liver cancer need to be developed. We demonstrated that GA induced apoptosis via the mitochondrial pathway in two types of liver cancer cells. p53 protein is a crucial factor in cellular stress responses and acts as an essential tumor suppressor (14). Upon activation, p53 controls the signaling process associated with the cell cycle based on the severity of the DNA damage. Thus, it can inhibit cell cycle progression or induce apoptosis. More than $50 \%$ of human tumors have been reported to have p53 mutations which affect p53 function. We found that GA induced caspase-associated apoptotic pathway which is important for induction of caspaseregulated apoptosis. We detected caspase protein in both cancer cells. The two HCC cell lines differ in the expression of one tumor suppressor protein, p53. Hep3B is with deleted p53 while Huh7 has mutated p53. Both cells are p53 deficient. p53, also known as tumor protein 53, is a tumor suppressor protein that in humans is encoded by the TP53 gene. p53 plays a crucial role in regulation of the cell cycle. The functions of the tumor suppressor gene have become an important target to prevent cancer. As such, p53 has been described as 'the guardian of the genome' due to its pivotal role in conserving the stability of genome and preventing mutation (14). p53 tumor suppressor is one of our defenses against damage due to radiation, carcinogens and viruses. When DNA damage occurs, p53 levels rise and initiate protective measures. p53 binds to several regulatory sites in the genome that consequently halts cell division through the process of programmed cell death, or apoptosis. The mediation of $\mathrm{p} 53$ provides a common drug target for cancer development. However, the regulation of cell cycle in p53-deficient cells may be through different apoptotic pathways. A recent study showed that p53 can mediate apoptosis by repression of HPV oncogenes and upregulation of tumor suppressor proteins in human cancer cells (15). Hep3B contains an integrated hepatitis B virus (HBV) genome in the cell which is highly associated with HCC development. However, the present findings showed that GA induces apoptosis in Hep3B and Huh7 cell death through caspases and is independent of p53-associated pathway. The results suggest the operative role of GA may be involved in killing $\mathrm{HBV}$ genome integrated in $\mathrm{HCC}$ through regulation of other apoptotic processes. A previous study indicated that GA has no influence on the viability of primary cultured rat hepatocytes (16), suggesting that GA causes less harm to normal liver cells than to its cancer counterparts. These findings also reveal that the apoptosis of liver cancer cells is regulated by different complex systems involving large numbers of molecules and that GA-mediated signaling is only part of the regulatory system. The existence of the p53-independent regulatory signals in apoptosis in liver cancer cells may represent an alternate approach for inhibition of cancer cell growth to avoid complete liver damage. To investigate the possible mechanism that led to the cell death of Hep3B and Huh7 cells, different parameters related to apoptosis including cell shrinkage and budding, DNA fragmentation and condensation, as well as cytosolic DNA content were measured. Both the death receptor pathway and the mitochondrial pathway were found to be involved in GA-induced apoptosis. Several studies showed that Bid is an important pro-apoptotic protein in crosslinking the extrinsic cell death receptor signaling pathway to mitochondria upon caspase-8-mediated cleavage (17). These findings are consistent with the previous report that integration of Bax and $\mathrm{tBid}$ to the outer membrane followed by the release of cytochrome $c$ is a possible prerequisite for the mitochondrial apoptotic pathway $(13,18)$. GA induces apoptosis in p53-deficient cancer cells. GA exerts inhibitory effects on Hep3B and Huh7 cell lines through similar mode of action. Based on these results, it seems unlikely that GA-induced apoptosis is due to the p53 status. This study showed the anticancer activity of GA is mediated via both the caspases in the extrinsic death receptor pathway and the mitochondria-dependent pathway. The present study demonstrated that deletion or deficiency of p53 does not affect cell cycle. The present results indicate that GA positively regulates the cancer cell apoptosis. Therefore, GA activity in liver cancer cells may represent one of the molecular mechanisms involved in anticancer agent-induced apoptosis. The low concentration of GA towards cancer cells is one of the fundamental criteria for efficient drug development and targeting. The results suggest that GA can be developed as an anticancer drug for p53-deficient cancer cells. The present study on GA may provide a promising therapeutic strategy for different types of liver cancer. 


\section{Acknowledgements}

This study was in part supported by grant no. 6903292 kindly provided by Luck Tissue MFY Ltd. We thank Mr. Matt Cheung for his technical assistance.

\section{References}

1. Asano J, Chiba K, Tada M and Yoshii T: Cytotoxic xanthones from Garcinia hanburyi. Phytochemistry 41: 815-820, 1996.

2. Li S, Song JZ, Han QB, Qiao CF and Xu HX: Improved highperformance liquid chromatographic method for simultaneous determination of 12 cytotoxic caged xanthones in gamboges, a potential anticancer resin from Garcinia hanburyi. Biomed Chromatogr 22: 637-644, 2008.

3. Nie F, Zhang X, Qi Q, Yang L, Yang Y, Liu W, Lu N, Wu Z, You $Q$ and Guo Q: Reactive oxygen species accumulation contributes to gambogic acid-induced apoptosis in human hepatoma SMMC-7721 cells. Toxicology 260: 60-67, 2009.

4. Palempalli UD, Gandhi U, Kalantari P, Vunta H, Arner RJ, Narayan V, Ravindran A and Prabhu KS: Gambogic acid covalently modifies IkappaB kinase-beta subunit to mediate suppression of lipopolysaccharide-induced activation of NF-kappaB in macrophages. Biochem J 419: 401-409, 2009.

5. Shu W, Chen Y, Li R, Wu Q, Cui G, Ke W and Chen Z: Involvement of regulations of nucleophosmin and nucleoporins in gambogic acid-induced apoptosis in Jurkat cells. Basic Clin Pharmacol Toxicol 103: 530-537, 2008.

6. Chen J, Gu H, Lu N, Yang Y, Liu W, Qi Q, Rong J, Wang XT, You QD and Guo QL: Microtubule depolymerization and phosphorylation of c-Jun N-terminal kinase-1 and p38 were involved in gambogic acid induced cell cycle arrest and apoptosis in human breast carcinoma MCF-7 cells. Life Sci 83: 103-109, 2008.

7. Bortner CD and Cidlowski JA: Cell shrinkage and monovalent cation fluxes: role in apoptosis. Arch Biochem Biophys 462: 176-188, 2007.

8. Oberhammer FA, Hochegger K, Fröschl G, Tiefenbacher R and Pavelka M: Chromatin condensation during apoptosis is accompanied by degradation of lamin $\mathrm{A}+\mathrm{B}$, without enhanced activation of cdc2 kinase. J Cell Biol 126: 827-837, 1994.
9. Bonfoco E, Krainc D, Ankarcrona M, Nicotera P and Lipton SA: Apoptosis and necrosis: two distinct events induced, respectively, by mild and intense insults with N-methyl-D-aspartate or nitric oxide/superoxide in cortical cell cultures. Proc Natl Acad Sci USA 92: 7162-7166, 1995.

10. Duke RC and Cohen JJ: IL-2 addiction: withdrawal of growth factor activates a suicide program in dependent $\mathrm{T}$ cells. Lymphokine Res 5: 289-299, 1986.

11. Nechushtan A, Smith CL, Hsu YT and Youle RJ: Conformation of the Bax C-terminus regulates subcellular location and cell death. EMBO J 18: 2330-2341, 1999.

12. Zhang S, Zhao S, Bai L, Guan M, Mo J and Lan L: Melatonin restores normal $\mathrm{Bax}$ and $\mathrm{Bcl}-2$ protein expression in the subgranular zone of the dentate gyrus in pinealectomized rats. Neural Regen Res 6: 2129-2133, 2011.

13. Gross A, Jockel J, Wei MC and Korsmeyer SJ: Enforced dimerization of BAX results in its translocation, mitochondrial dysfunction and apoptosis. EMBO J 17: 3878-3885, 1998.

14. Latonen L and Laiho M: Cellular UV damage response - functions of tumor suppressor p53. Biochim Biophys Acta 1755: 71-89, 2005.

15. Munagala R, Kausar H, Munjal C and Gupta RC: Withaferin A induces $\mathrm{p} 53$-dependent apoptosis by repression of HPV oncogenes and upregulation of tumor suppressor proteins in human cervical cancer cells. Carcinogenesis 32: 1697-1705, 2011.

16. Yang Y, Yang L, You QD, Nie FF, Gu HY, Zhao L, Wang XT and Guo QL: Differential apoptotic induction of gambogic acid, a novel anticancer natural product, on hepatoma cells and normal hepatocytes. Cancer Lett 256: 259-266, 2007.

17. $\mathrm{Li} \mathrm{H}, \mathrm{Zhu} \mathrm{H}, \mathrm{Xu} \mathrm{C}$ and Yuan J: Cleavage of BID by caspase mediates the mitochondrial damage in the Fas pathway of apoptosis. Cell 94: 491-501, 1998.

18. Li L, Lu N, Dai Q, Wei L, Zhao Q, Li Z, He Q, Dai Y and Guo Q: GL-V9, a newly synthetic flavonoid derivative, induces mitochondrial-mediated apoptosis and G2/M cell cycle arrest in human hepatocellular carcinoma HepG2 cells. Eur J Pharmacol 670: 13-21, 2011. 